\title{
High-Precision Surface Profiling Using Multi-Hundred Watts Ultrashort Pulse Lasers and Ultrafast Polygon-Mirror Based Scanner
}

\author{
Stefan Mauersberger ${ }^{1}$, Joerg Schille ${ }^{1}$, Kristian Kujawa ${ }^{1}$, Lutz Schneider ${ }^{1}$, \\ Christoph Million ${ }^{2}$, Konrad Hartung ${ }^{2}$, Karsten Oehlert ${ }^{2}$ and Udo Loeschner \\ ${ }^{1}$ University of Applied Sciences Mittweida, Laserinstitut Hochschule Mittweida, \\ Technikumplatz 17, 09648 Mittweida, Germany \\ E-mail:mauersbe@hs-mittweida.de \\ ${ }^{2}$ Jade Hochschule Wilhelmshaven/Oldenburg/Elsfleth, Institut für Energie- und Verfahrenstechnik, \\ Friedrich-Paffrath-Straße 101, 26389 Wilhelmshaven, Germany
}

\begin{abstract}
High-precision surface profiling is studied by using ultrashort pulse lasers up to $450 \mathrm{~W}$ laser powers and $40 \mathrm{MHz}$ maximum pulse repetition frequency. A polygon-mirror based scan system is applied for ultrafast and flexible laser beam raster scanning providing up to $560 \mathrm{~m} / \mathrm{s}$ laser beam moving speeds. By investigating the high-average power picosecond and femtosecond laser systems in large-area processing, optimum parameter settings are derived with regard to machining quality, efficiency and throughput. In addition, the influence of the focus spot size on top width and tip angle of trapezoidal micro structures (Riblets) is evaluated. Inspired by bionic surface functionalities, the laser made Riblets are tested in a Goettingen-type wind tunnel to identify their effectiveness for aerodynamic drag reduction in turbulent flows. For the optimum Riblet geometries, a maximum total pressure loss reduction of $1.76 \%$ is achieved that is remarkable when comparing with literature data. The drag reducing effect of the Riblets is further confirmed by empirical-analytical and CFD analyses showing up to $6.4 \%$ skin friction reduction. By taking into account the effective processing time of $6.0 \mathrm{~cm}^{2} / \mathrm{min}$ with potential to be further scaled-up with higher laser powers, ultrafast laser-based Riblet profiling could be a key enabling technology to enhance the operational performance in the energy machinery sector.
\end{abstract}

DOI: $10.2961 /$ jlmn.2020.01.2004

Keywords: ultrashort pulse laser, high power laser, high-rate, surface profiling, Riblet, bionic

\section{Introduction}

High-rate laser material processing by combining powerful ultrashort pulse lasers with high-speed laser beam scanning seems to be a key enabling technology for highthroughput and precision micro fabrication $[1,2]$. In particular, ultrafast laser beam movement of hundreds meters per second and above is the core feature to bring high-average power lasers supplying multi-hundreds Watts from the laboratory state to industrial production. In fact, this is valuable for power scaling in high-volume laser machining as the processing rates scale-up with pulse repetition frequency and average laser powers. Hereby, the main advantage of the ultrafast laser beam moving speed is avoiding adverse effects on laser beam matter interactions even for MHz-repetitive laser pulses. So, it has already been reported for highly-repetitive ultrashort pulses that both machining quality and processing efficiency suffer from high thermal load to the substrates resulting in material melting as well as beam shielding losses affected by pulse - plasma/particle interactions. However, high-rate machining by speeding up the laser beam can overcome the main limitations of highly-repetitive ultrashort pulses when applied at comparably slow speeds, thus in order to sustain high processing quality and removal efficiency in high-throughput micro machining. This will be demonstrated in the following by the example of high-rate surface profiling using an ultrashort pulse laser with up to $450 \mathrm{~W}$ laser powers and $40 \mathrm{MHz}$ maximum pulse repetition frequency. For ultrafast and flexible laser beam raster scanning, an in-house developed polygon-mirror based biaxial scan system was applied providing up to $560 \mathrm{~m} / \mathrm{s}$ laser beam moving speeds.

In the presented study investigating powerful picosecond and femtosecond laser beams, the peak fluence, pulse repetition frequency, average laser power and scan speed were varied in order to evaluate their influence on materials ablation. Based on the results obtained, the dependency of the studied processing parameters on the removal rate will be discussed and optimum parameter settings will be derived with regard to machining quality, efficiency and throughputs. Inspired by bionic surface functionalities, large-area Riblet production will be presented to demonstrate the potential of the high-rate laser profiling method for innovative surface engineering and productions. Laser made Riblet structures on surfaces in turbulent flows have already proven efficient to reduce skin friction drag and total pressure losses [3-5].

From this point of view, laser made Riblets provide a great potential to significantly increase performance and efficiency in the energy machinery sector, however, the high demand on the Riblet profile accurateness, low applied laser powers and the long processing times of only a few $\mathrm{cm}^{2} / \mathrm{h}$ hindered so far the industrial implementation of this innovative technology. These technological limitations can be overcome by high-rate machining using high-average laser powers in combination with ultrafast processing speeds that will be addressed in the following by the example of high-precision Riblet profiling. 


\section{Ideal Riblet geometry}

Riblets represent rib-shaped micro-scale groove structures directed longitudinal along the flow of a fluid over a solid surface. They act to avoid interactions between the turbulent boundary layer and solid surface to be effective to reduce wall shear stress and skin friction drag. This is valuable for enhancing the operational performance of a large number of aerodynamic and hydrodynamic systems, e.g., windmill blades, turbine blades, aircraft wings, propellers, pipeline or ship applications, etc. The characteristic geometry parameters of trapezoidal Riblet structures are illustrated in Fig. 1 with Riblet spacing, $s$, Riblet height, $h$, top width, $t$, and tip angle, $\alpha$, calculated from the taper angle, $\beta$, of the Riblet walls. However, in order to achieve maximum skin friction drag reductions, the ideal Riblet geometry to be processed depends on the local flow characteristics.

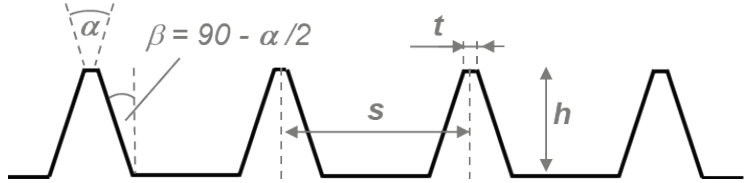

Fig. 1 Definition of the characteristic geometry parameters of trapezoidal Riblet structures.

In Fig. 2, as an example, the optimum Riblet spacing is calculated for the NREL S819 airfoil in the turbulent flow regime. The optimum Riblet spacing varies depending on the specific position along the airfoil length. As almost ideal value, a Riblet spacing of about $124 \mu \mathrm{m}$ can be seen as effective over a great length along the given airfoil profile.

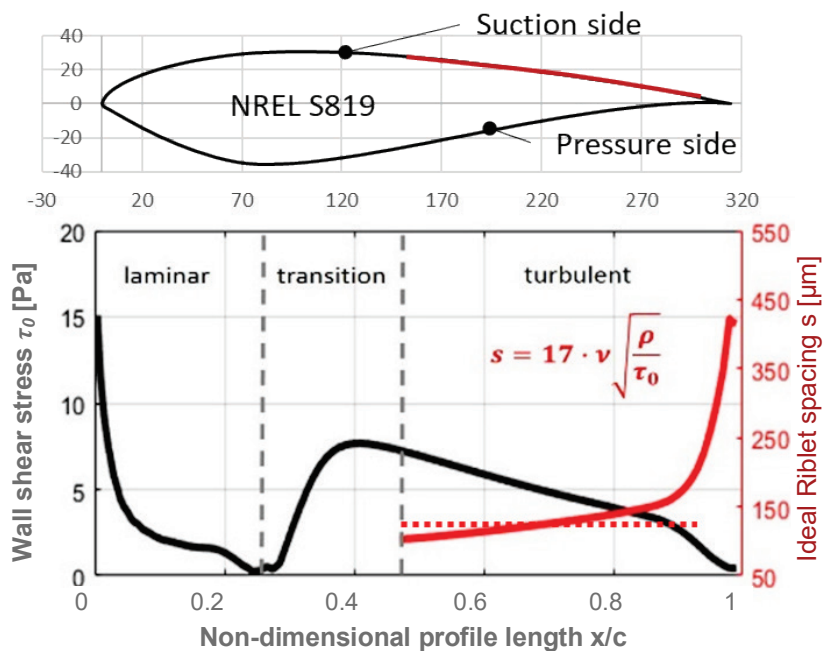

Fig. 2 Riblet spacing calculated for the NREL S819 airfoil as function of the specific position $x$ along the airfoil length $c$; the Reynolds number $\operatorname{Re}=10^{6}$ is considered in the calculations.

For most effective trapezoidal Riblets, the optimum Riblet height is given by half of Riblet spacing, the top width should be as small as possible and the tip angle should be $30^{\circ}$ [6]. From this structural preconditions, several pre-investigations on flat plates were realized in order to optimise the laser profiling process parameters. Therefore, the following Riblet profile geometry is considered to be the optimum for the application on flat plates:

$\begin{array}{ll}\text { Riblet spacing: } & s=124 \mu \mathrm{m} \\ \text { Riblet height: } & h=62 \mu \mathrm{m} \\ \text { Top width: } & t<10 \mu \mathrm{m} \\ \text { Tip angle: } & \alpha=30^{\circ}\end{array}$

\section{Analytical model to predict Riblet profiles}

An analytical model is developed and applied to predict the resulting Riblet profile with the goal to adjust the parameter settings to be used in precision laser profiling. For a laser beam with Gaussian intensity distribution following Equation (1), and by taking into account Beer 's law, the ablation profile resulting from single pulse irradiation can be calculated by Equation (2). Herewith, $H_{0}$ is the peak fluence as calculated from the pulse energy $Q_{\mathrm{P}}$ in Equation (3), $w_{\sigma, 0}$ is the beam waist radius based on second order moments, $d_{Z}$ is the crater depth, $H_{\text {th }}$ is the threshold fluence, and $\delta$ is the effective penetration depth.

$$
\begin{gathered}
H(r)=H_{0} \cdot \exp \left(-\frac{2 \cdot r^{2}}{w_{\sigma, 0}^{2}}\right) \\
d_{Z}(r)=-\delta\left[\ln \left(\frac{H_{\mathrm{th}}}{H_{0}}\right)+\frac{2 r^{2}}{w_{\sigma, 0}^{2}}\right] \\
H_{0}=\frac{2 Q_{\mathrm{P}}}{\pi w_{\sigma, 0}^{2}}
\end{gathered}
$$

Fig. 3 shows the ablated crater profile as function of fluence as the crater depth increases with higher applied fluence. Further, it becomes clear that the taper of the crater walls increases with greater crater depths. From this knowledge it can be concluded a greater depth is more likely the effect for steeper walls than the fluence. However, it should be mentioned here, thus to avoid misinterpretation of Fig. 3, the diameter of the modelled ablation craters scales in micrometer, as the depth is illustrated at nanometer scale.

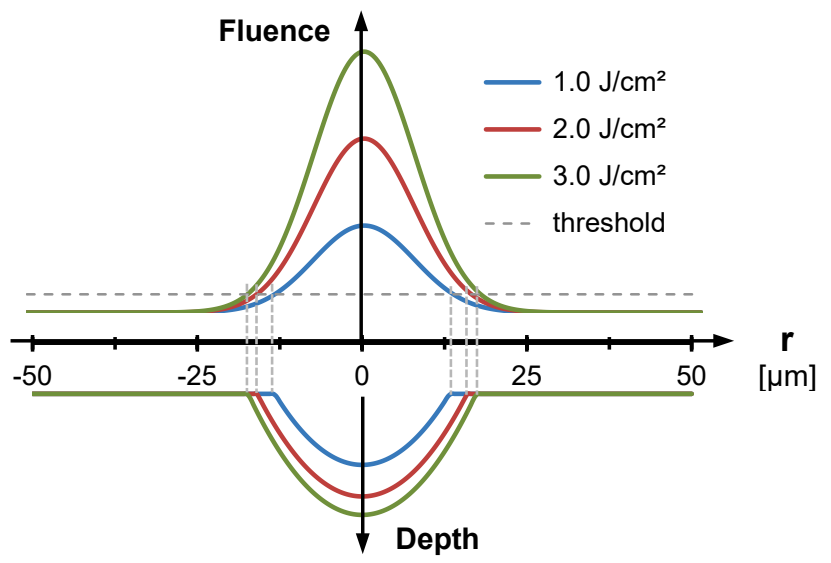

Fig. 3 Crater profiles calculated for pulses of various fluence.

The volume of a crater ablated by a single pulse can theoretically be determined by integrating the crater depth profile, as described and experimentally validated elsewhere [7-9]. For moving beams, however, the exact shape of the removed volume will be given by expanding this simulation to overlapping pulses [10]. Based on this approach, Fig. 4 plots fluence (top) and resulting depth profile (bottom) for eleven irradiated pulses moving along the $x$-axis at equidistant lateral pulse spacing $d x$.

$$
z(x)=\delta \cdot \sum_{i=1}^{n}\left[\ln \left(\frac{H_{t h}}{H_{0}}\right)+\frac{2 \cdot(x-i \cdot d x)^{2}}{w_{\sigma, 0}^{2}}\right]
$$

The resulting depth profile is calculated according to Equation (4) for pulses of $1.2 \mathrm{~J} / \mathrm{cm}^{2}$ peak fluence, $15 \mu \mathrm{m}$ focus radius, $5 \mu \mathrm{m}$ pulse spacing and by taking into account 
$0.1 \mathrm{~J} / \mathrm{cm}^{2}$ threshold fluence and $18 \mathrm{~nm}$ effective penetration depth. For clarity, only the pulse numbers 1 to 4 as well as 10 and 11 are illustrated in this figure.

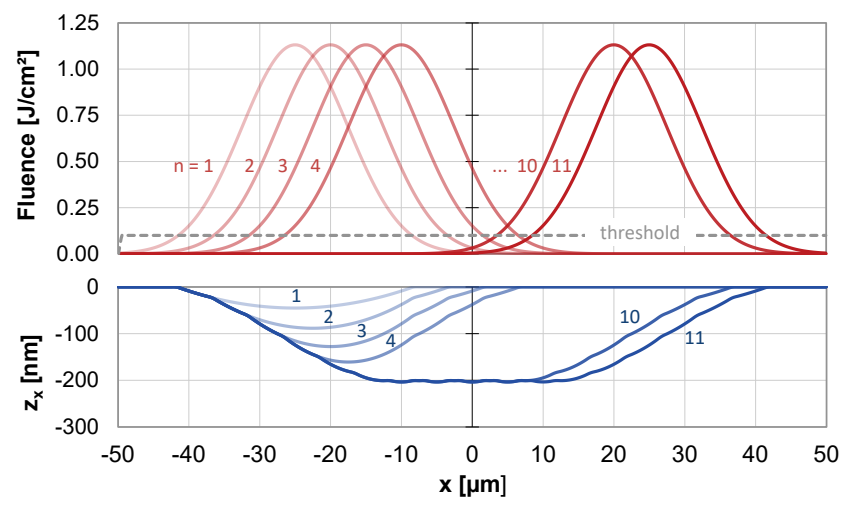

Fig. 4 Fluence (top) and resulting depth profile (bottom) for 11 irradiated pulses moving along $\mathrm{X}$-axis at equidistant lateral pulse spacing $d x$; colors changing from light to dark indicate higher the total optical energy input.

The simulation model was enhanced to sum up the depth profile of each individual scanned line in order to estimate the depth profile of the cavities engraved in parallel linescanning procedure, see Fig. 5 illustrates the resulting depth profile computed for different focus spot diameters ranging between $10 \mu \mathrm{m}$ and $46 \mu \mathrm{m}$. As the number of impinging pulses varied depending on the considered spatial pulse distance, herewith spatial pulse and line distances half of the respective spot radii were used, the number of scan crossings was varied in a way to produce $50 \mu \mathrm{m}$ profile depth here.

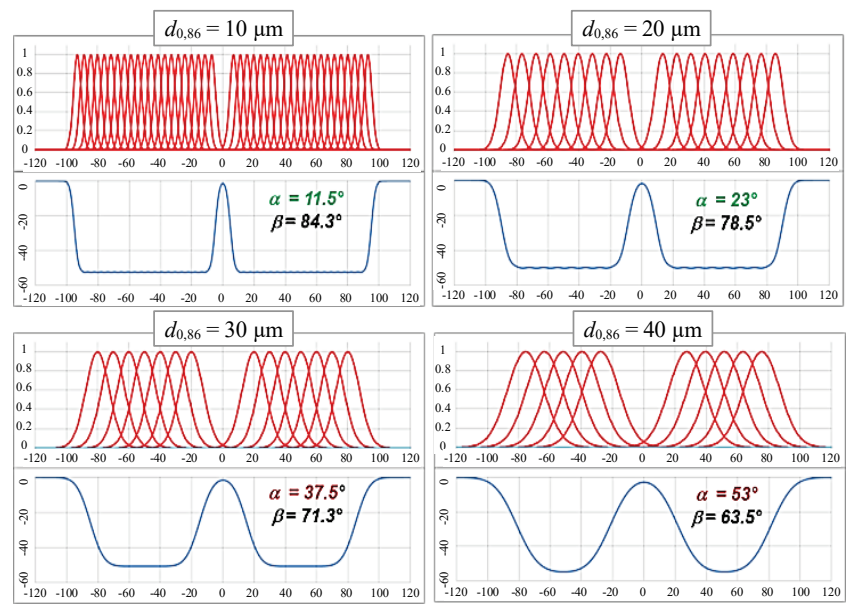

Fig. 5 Depth profile computed for different focus spot diameters $d_{0,86}$ ranging between $10 \mu \mathrm{m}$ and $46 \mu \mathrm{m}$; the taper angle $\beta$ and respective tip angle $\alpha$ are indicated, the fluence was $1.2 \mathrm{~J} / \mathrm{cm}^{2}$, the number of scan passes was varied to achieve the requested $50 \mu \mathrm{m}$ Riblet height.

It can further be seen in Fig. 5, the steepest taper angle will be achieved with the smallest focus spot, in fact decreasing from $84.3^{\circ}$ to $63.5^{\circ}$ for the spot diameters enlarging from $10 \mu \mathrm{m}$ to $46 \mu \mathrm{m}$, respectively. The resulting tip angle $\alpha$ of the arising Riblet profile can be easily approximated from the taper angle $\beta$ by the following simple equation

$$
\alpha=2\left(90^{\circ}-\beta\right)
$$

where the taper angle calculates as function of profile depth $D$ and focus spot radius $w$ according to

$$
\beta=\arctan \left(\frac{D}{w}\right)
$$

From the calculated Riblet profiles it becomes clear, the candidate tip angle for functional Riblet can only be reached with $10 \mu \mathrm{m}$ and $20 \mu \mathrm{m}$ focus spot diameter. However, the profile calculations carried out in this work give evidence that even for large spot diameters wall angles steeper than $75^{\circ}$, or rather tip angles smaller than $30^{\circ}$, can be achieved at larger profile depths. This is indicated in Fig. 6 plotting the taper angle as function of profile depth. For different focus spot diameters ranging between $10 \mu \mathrm{m}$ and $46 \mu \mathrm{m}$, the respective profile depths for either taper angle larger than $75^{\circ}$ or tip angles smaller than $30^{\circ}$ are highlighted in this figure. It is shown that a taper angle greater than $75^{\circ}$ can be achieved with $10 \mu \mathrm{m}$ spot diameter at $19 \mu \mathrm{m}$ profile depth, for the $46 \mu \mathrm{m}$ spot diameter the corresponding profile depth measures greater than $86 \mu \mathrm{m}$.

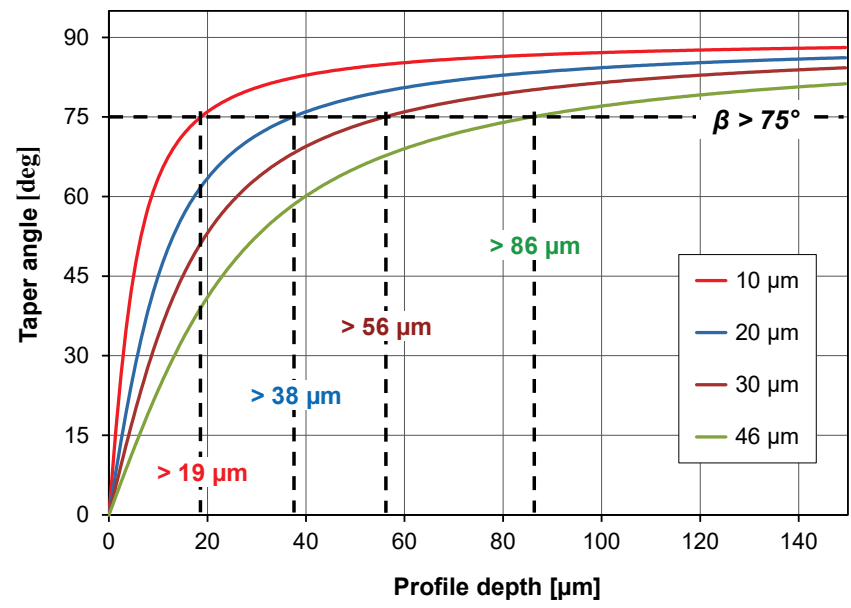

Fig. 6 Taper angle calculated as function of profile depth for focus spot diameters ranging between $10 \mu \mathrm{m}$ and $46 \mu \mathrm{m}$, the respective profile depths for either taper angle larger than $75^{\circ}$ or tip angles smaller than $30^{\circ}$ are highlighted.

\section{Experimental methods}

In the experimental study, a variety of ultrashort pulse laser systems were applied. This provided a wide range of complementary processing parameter settings to be investigated on AISI 304 (X5CrNi18-10) stainless steel and EN-AW 5005A (AlMg1) Aluminum alloy metal sheets. In all experiments, the sample surface was positioned in the focal plane. The smallest experimentally studied focus spot diameter was $20 \mu \mathrm{m}$ that was supplied by focusing a femtosecond laser beam of $515 \mathrm{~nm}$ wavelength and $400 \mathrm{fs}$ pulse duration and using a $160 \mathrm{~mm} \mathrm{f}$-theta lens. For the larger focus spots, a laser beam of $1030 \mathrm{~nm}$ and $400 \mathrm{fs}$ was focused by either a $167 \mathrm{~mm}$ or $255 \mathrm{~mm}$ objective to achieve focus spot diameters of $30 \mu \mathrm{m}$ and $46 \mu \mathrm{m}$, respectively.

At first, in the fundamental experimental work on laser profiling and Riblet formation, comparably low average laser powers up to $5.5 \mathrm{~W}$ were irradiated to the samples at $1.03 \mathrm{MHz}$ pulse repetition frequencies. Herewith, a galvanometer scan system was used to deflect the laser beam at $5 \mathrm{~m} / \mathrm{s}$ scan speed thus to provide the required $5 \mu \mathrm{m}$ spatial pulse distance. Secondly, to demonstrate scaling-up the profiling machining process with increasing average powers, both a picosecond laser delivering $10 \mathrm{ps}$ pulses at $230 \mathrm{~W}$ and a femtosecond system supplying $350 \mathrm{fs}$ pulses at $450 \mathrm{~W}$ 
maximum average laser powers were studied. For efficient processing even at such high average powers, and further to avoid laser beam shielding losses and thermal loading, highly repetitive pulses up to $40 \mathrm{MHz}$ were deflected at extremely high $560 \mathrm{~m} / \mathrm{s}$ beam moving speeds. For this highspeed beam scanning, a polygon-mirror based scan system was implemented instead of the galvanometer scanner, the latter providing only $18 \mathrm{~m} / \mathrm{s}$ maximum scan speeds.

The machined Riblet structures were analyzed by using the confocal microscope VK-X260K (Keyence) for topography and profile depths measurements. The high precision of machining was visualized by scanning electron microscope (SEM) micrographs captured with the JSM-6510LV (JEOL) The functionality of the laser made Riblet was evaluated by wind channel measurements in turbulent flows. From these measurements, the overall drag reduction was deduced by the ratio of the respective pressure loss coefficient $\Delta \omega / \omega_{0}$ determined for both the smooth and the Riblet metal plates. In order to validate the drag reducing effect, the Riblet profiles were further analyzed by an empirical-analytical and a numerical approach to predict the achievable wall shear stress reduction with reference to the smooth surface $\Delta \tau / \tau_{0}$. In addition, to relate the predicted wall shear stress reduction to the wind tunnel measurements, the reduction of the pressure loss coefficients $\Delta \omega / \omega_{0}$ and wall shear stress reduction $\Delta \tau / \tau_{0}$ were computed by Computational Fluid Dynamic (CFD) methods [11]. It is noteworthy, therefore, streamwise wall shear stresses cause skin friction drag, for example reported for an Airbus A340-300, that contribution to the total drag of the aircraft was about 48\% [3].

\section{Experimental results and discussions \\ 5.1 Characteristics of laser profiling}

Fig. 7 shows SEM micrographs of Riblets as representative examples for the micro structures made by high-precision laser surface profiling. The Riblets were machined in AISI 304 by multiple raster-scanning a $1030 \mathrm{~nm}$ femtosecond laser beam of $30 \mu \mathrm{m}$ focus spot diameter, $4.3 \mathrm{~W}$ applied average laser powers, and $1.03 \mathrm{MHz}$ pulse repetition frequency at $5 \mathrm{~m} / \mathrm{s}$ scan speed. The shown Riblet structures vary in their spacing and height as produced by increasing the number of adjacent lines within the raster scan pattern as well as the number of repeated scan passes. In this manner, the Riblet height corresponds to the depth of the laser machined cavities double-sided the remaining walls (Riblet). Due to the fact that none rectangular side-walls could be produced, the resulting height profile corresponded to a trapezoidal Riblet shape.

Following a general trend in laser micro processing, the cavity depth, or rather Riblet height, increased almost linearly with increasing number of scan passes. This is exemplified in Fig. 8 a by three-dimensional (3D) topography measurements on Riblets produced with $105 \mu \mathrm{m}$ spacing. These Riblets were machined by using a laser beam of $20 \mu \mathrm{m}$ focus spot diameter and $1.0 \mathrm{~J} / \mathrm{cm}^{2}$ fluence. The cavity depth increased from $8.8 \mu \mathrm{m}$ achieved with 30 scan passes to $112.0 \mu \mathrm{m}$ at 360 scans. The aforementioned linearly increase of the cavity depth with increasing number of scan passes is confirmed by the experimental data given in the plot of Fig. 8 b. The Riblet top width was typically measured below $10 \mu \mathrm{m}$ for the cavities with depths greater than $50 \mu \mathrm{m}$. It can also be seen that the experimental cross section profiles extracted from the topography measurements (symbols) are in good agreement with the computed ablation profiles (solid lines). Therefore, in the ablation profile computation following Equation (4), the fluence of $1.0 \mathrm{~J} / \mathrm{cm}^{2}$ and a varied number of scan passes applied in the ablation experiments were used, while the material-specific values were set to: threshold fluence of $0.07 \mathrm{~J} / \mathrm{cm}^{2}$ or $0.1 \mathrm{~J} / \mathrm{cm}^{2}$ and effective penetration depth of $12 \mathrm{~nm}$ or $18 \mathrm{~nm}$ for the $515 \mathrm{~nm}$ or $1030 \mathrm{~nm}$ laser beam, respectively, as well as a constant pulse and hatch distance of $5 \mu \mathrm{m}$ was considered.

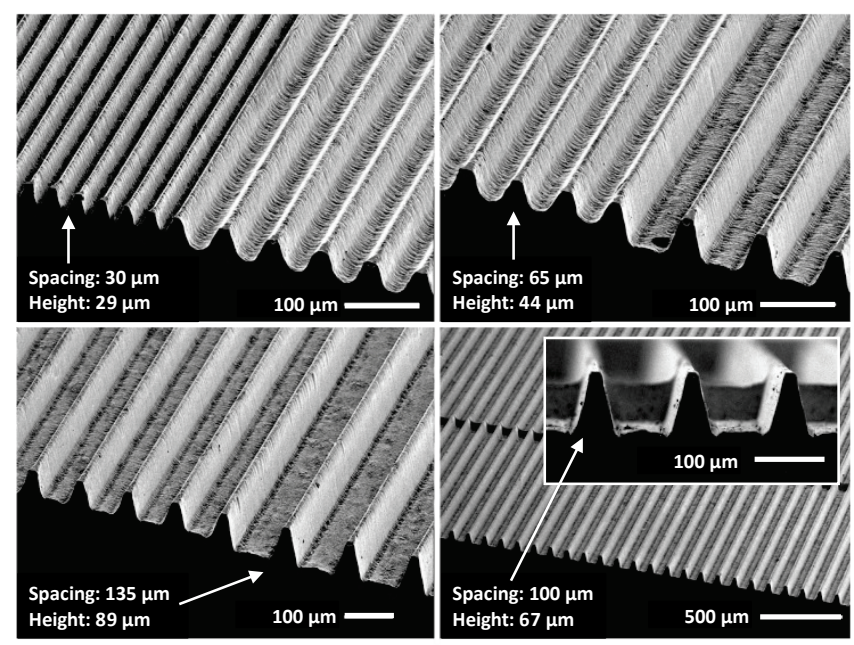

Fig. 7 Riblet structures made in AISI 304 by multiple raster-scanning a laser beam of $1030 \mathrm{~nm}, 390 \mathrm{fs}, 1.03 \mathrm{MHz}, 30 \mu \mathrm{m}$ focus diameter and $4.3 \mathrm{~W}$ average laser power.

Exceptionally, the taper angles of the deeper laser processed cavities deviate from the computed profiles. It should be mentioned, therefore, that side-wall effects, i.e., dependence of reflectivity on angle of incidence, re-deposition of ablated material, etc., are not considered in the ablation model. In particular, re-deposition of ablated material at the cavity walls comes into greater effect at the deeper cavities. This effect is illustrated by the polished cross section micrograph included in Fig. $8 \mathrm{c}$ (right). The taper angles were measured above $75^{\circ}$ at cavities with depths greater than $40 \mu \mathrm{m}$. Such steep cavity walls fulfill the geometric precondition on functional Riblets regarding their tip angle.

As another effect, the influence of the focus spot diameter on both taper angle and top width is emphasized in Fig. 8. By comparing the data presented in Fig. $8 \mathrm{c}$ and d, it comes clear that steeper cavities could be produced with the smaller $20 \mu \mathrm{m}$ focus spot diameter compared to the larger ones of $30 \mu \mathrm{m}$. In detail, with a beam of $20 \mu \mathrm{m}$ focus spot size the taper angle was measured of $78^{\circ}$ at $43 \mu \mathrm{m}$ cavity depths. This angle was considerably greater than that obtained with the $30 \mu \mathrm{m}$ focus spot size of $70^{\circ}$ at $44 \mu \mathrm{m}$ depth. The respective tip angles correspond to $24^{\circ}$ versus $40^{\circ}$. It is worth mentioning that the smallest top width of the Riblets of $6 \mu \mathrm{m}$ was produced with the $20 \mu \mathrm{m}$ focus spot size. With the $30 \mu \mathrm{m}$ spot size the top width was larger than $10 \mu \mathrm{m}$. These findings are in good accordance with the computed Riblet profiles presented above. In conclusion, it is noteworthy that the profile requirements on functional Riblets could only be achieved with the $20 \mu \mathrm{m}$ focused laser beam.

Fig. 9 presents the tip angle as a function of Riblet height by the example of two materials, AISI 304 and Aluminum 
alloy EN-AW 5005A, as machined with different processing parameter settings. In Fig. 9 a, the tip angle of $30^{\circ}$ is highlighted by a red solid line indicating the objective goal for functional Riblet structures.
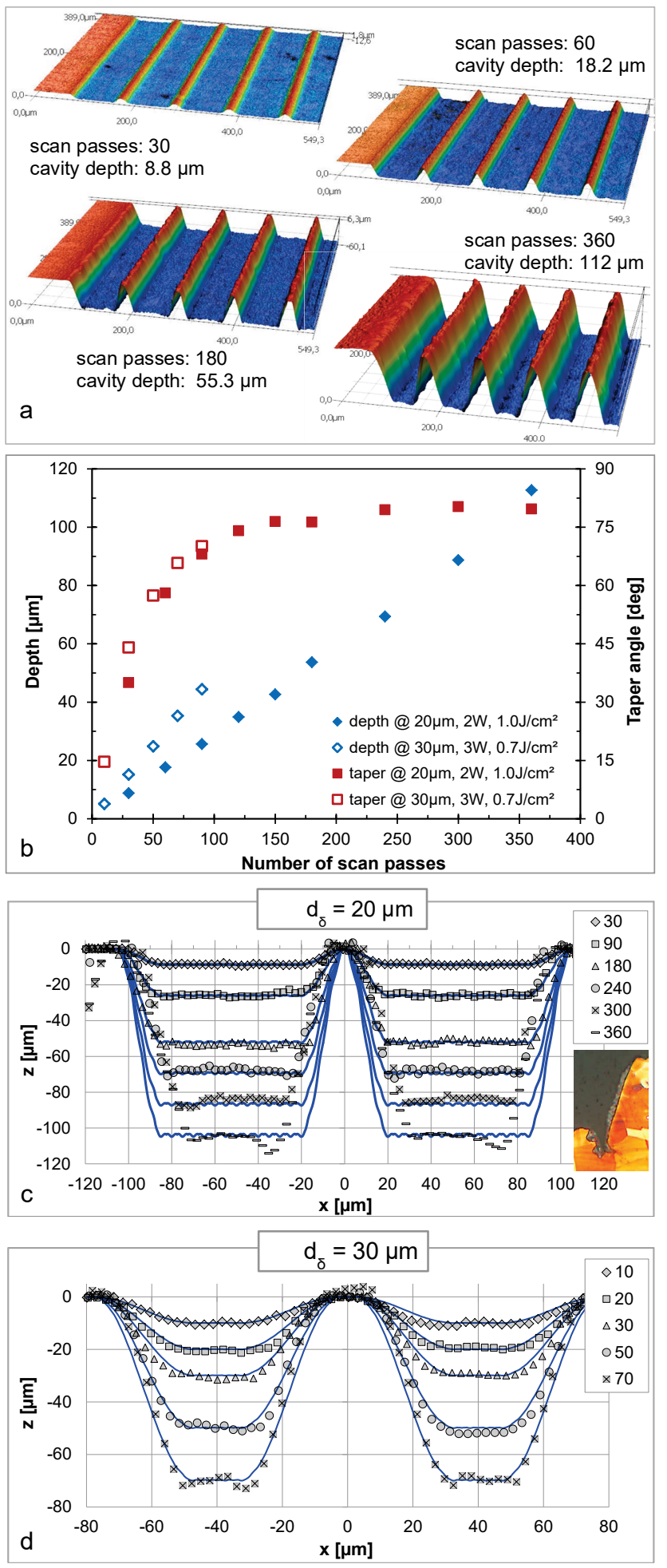

Fig. 8 a) 3D topography measurements on Riblets produced on AISI 304 with $105 \mu \mathrm{m}$ spacing, processing parameter settings were: $515 \mathrm{~nm}, 20 \mu \mathrm{m}$ focus spot, $1.0 \mathrm{~J} / \mathrm{cm}^{2}$ fluence, scan passes between 30 and 360 ; b) functional relation between cavity depth, taper angle and number of scan passes; Riblet formation as function of number of scan passes, experimental (symbols) and computed (solid lines) ablation profiles are shown, the focus spot diameter was varied between $20 \mu \mathrm{m}$ (c) and $30 \mu \mathrm{m}$ (d).
The figure shows the experimental results (symbols) in good correlation with the computed tip angles (dotted lines) within a wide range of investigated parameter settings. This, in turn, validates the proposed method to predict the resulting tip angle for diverse processing conditions. In detail, it is shown that tip angles smaller than $35^{\circ}$ cannot be produced with $46 \mu \mathrm{m}$ spot size. This was the case even for $120 \mu \mathrm{m}$ high Riblets as presented in the figure by the example of ENAW 5005A. However, tip angles much smaller than $30 \mu \mathrm{m}$ can be produced with the smaller focus spot sizes. This is figured out by the example of AISI 304 at $30 \mu \mathrm{m}$ and $20 \mu \mathrm{m}$ focus spot size for Riblet depths greater than $70 \mu \mathrm{m}$ or 40 $\mu \mathrm{m}$, respectively. Steeper Riblets walls with much smaller tip angles can be produced by further scaling down the focus diameter to $10 \mu \mathrm{m}$, as pointed out in Fig. 9 a by the computed data. As another effect, the polarization direction of the laser beam is influencing the resulting tip angle that is presented for the $20 \mu \mathrm{m}$ focus spot diameter. On AISI 304, the perpendicularly polarized laser beam (red symbols) led to less steep tip angles if compared with parallel polarized laser radiation (green symbols). An explanation therefore might be the lower absorptivity of laser radiation at perpendicular polarization state that will be confirmed in future experiments.
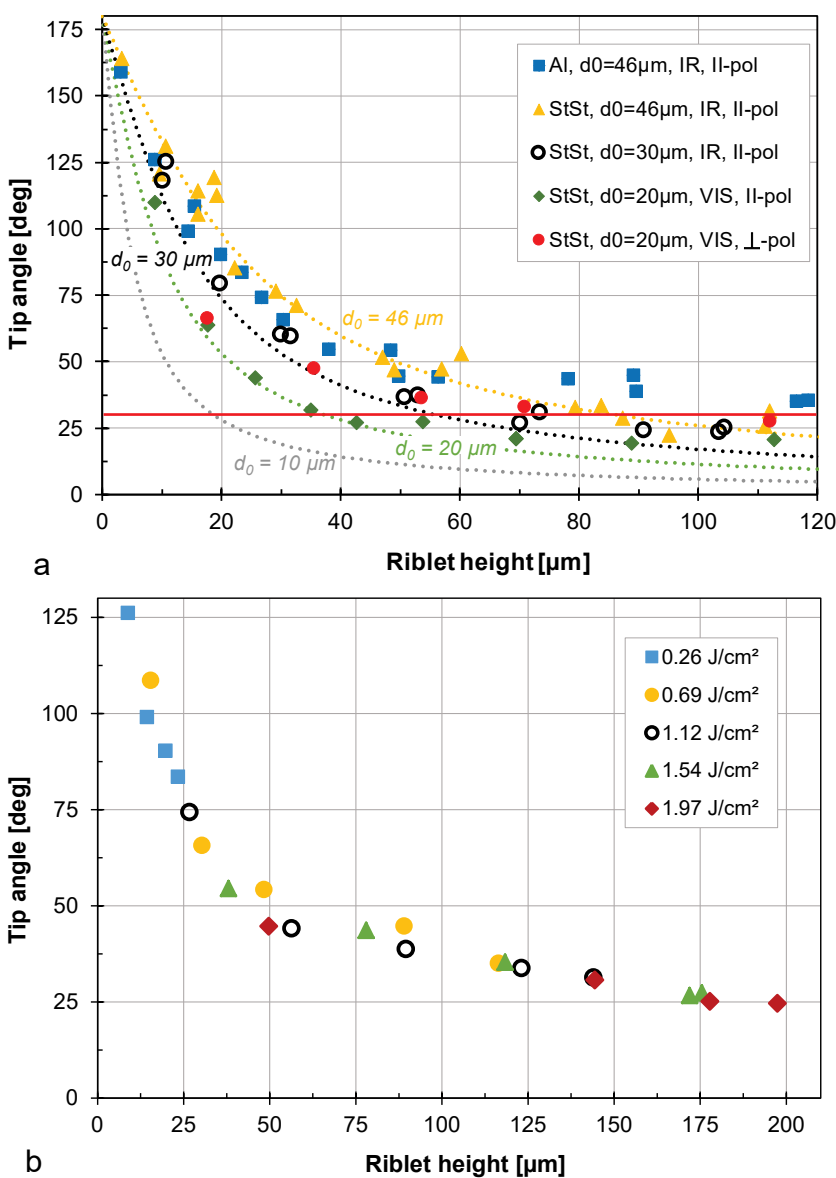

Fig. 9 Tip angle as function of Riblet height; a) focus spot diameter and polarization direction were varied on EN-AW 5005A and AISI 304 ; b) fluence was varied on EN-AW 5005A.

Another interesting finding in this study was the fluence of the irradiated ultrashort pulses has no significant influence on the tip angle. This can be seen in Fig. 9 b by the example of EN-AW 5005A. In the investigated fluence range starting 
slightly above the threshold fluence from $0.26 \mathrm{~J} / \mathrm{cm}^{2}$ to $1.97 \mathrm{~J} / \mathrm{cm}^{2}$ almost identical tip angles were achieved at a distinct Riblet height unaffected by the fluence. This verifies that both focus spot diameter and Riblet height, or rather cavity depth, have the greatest effects on the tip angle.

Fig. 10 illustrates 3D topography measurements and a cross section optical micrograph of Riblets having profile geometry very close to the predefined ideal Riblet geometry. The characteristic profile data of the Riblets were measured of $105 \mu \mathrm{m}$ spacing, $53 \mu \mathrm{m}$ height, $24^{\circ}$ tip angle and $5.8 \mu \mathrm{m}$ top width. The Riblets were machined with a $515 \mathrm{~nm}$ laser beam, $20 \mu \mathrm{m}$ focus spot diameter, $1.03 \mathrm{MHz}$ pulse repetition frequency, and $1.7 \mathrm{~W}$ average laser power.
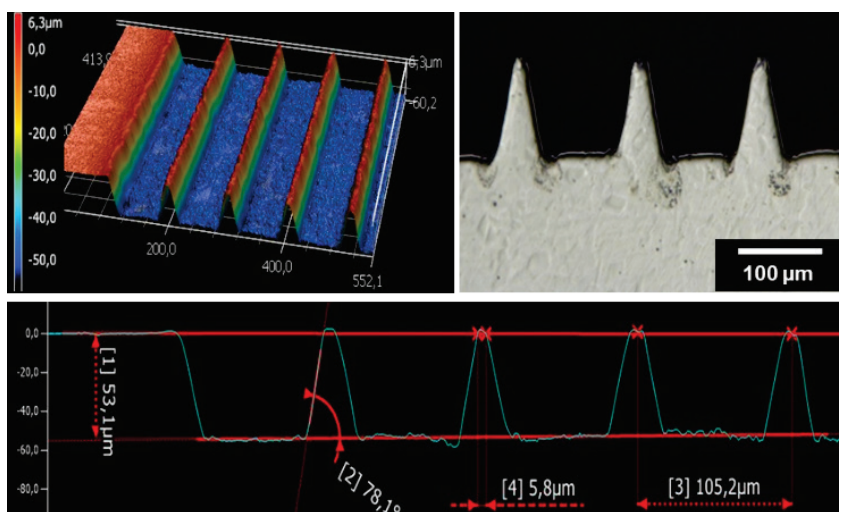

Fig. 10 Ideal Riblet geometry measured of $105 \mu \mathrm{m}$ spacing, $53 \mu \mathrm{m}$ height, $24^{\circ}$ tip angle and $5.8 \mu \mathrm{m}$ top width; processing parameter settings were: $515 \mathrm{~nm}, 20 \mu \mathrm{m}$ focus spot, $1.03 \mathrm{MHz}$ pulse repetition frequency, and $1.7 \mathrm{~W}$ average laser power.

\subsection{Scaling-up the processing rates}

The processing rate for the laser-made ideal Riblet structure shown in Fig. 10 was below $0.1 \mathrm{~cm}^{2} / \mathrm{min}$ that is clearly too slow for industrial production and manufacturing. However, high-rate laser machining seems a feasible technique to bring high-precision laser profiling from basic research to industrial-scale production. High-rate laser machining combines multi-hundreds Watt laser powers with ultrafast beam moving speeds capable to scale-up processing rates and machining throughputs increasing laser powers. In this way, the machining qualities can be maintained at sufficiently high level for precision micro processing, notwithstanding the fact that hundreds of Watts, extremely high, laser powers will be applied for high-speed machining. This is displayed in Fig. 11, comparing $62 \mu \mathrm{m}$ deep Riblets of constant $124 \mu \mathrm{m}$ spacing machined in AISI 304 with $1030 \mathrm{~nm}$ femtosecond pulses. The Riblets shown in Fig. 11 a were made by applying $3 \mathrm{~W}$ average laser powers at $1 \mathrm{MHz}$ and $5 \mathrm{~m} / \mathrm{s} \mathrm{scan}$ speed. The resulting volume ablation rate was as low as $1 \mathrm{~mm}^{3} / \mathrm{min}$. A considerably (almost linearly up-scaled) higher removal rate above $16 \mathrm{~mm}^{3} / \mathrm{min}$ was achieved with $60 \mathrm{~W}$ laser power, irradiated to the samples at $9.6 \mathrm{MHz}$ pulse repetition frequency.

However, as indicated in Fig. $11 \mathrm{~b}-\mathrm{d}$, the spatial pulse overlap affected the processing quality. With the low processing speed of $48 \mathrm{~m} / \mathrm{s}$ at the highest $9.6 \mathrm{MHz}$ pulse repetition frequency, the pulse spacing was as small as $5 \mu \mathrm{m}$. This low spatial pulse spacing along with very short inter-pulse delays and high applied laser powers induced a high thermal load to the substrates. In consequence of this, the material melted and re-solidified that, in turn, lowered the Riblet quality as exemplarily shown in Fig. $11 \mathrm{~b}$.

Another detrimental effect of the low spatial pulse distance at such high pulse repetition frequencies can be deduced from Fig. 11 e. The removal efficiency reduced from $0.28 \mathrm{~mm}^{3} / \mathrm{min} / \mathrm{W}$ at $20 \mu \mathrm{m}$ pulse spacing to $0.22 \mathrm{~mm}^{3} / \mathrm{min} / \mathrm{W}$ at $5 \mu \mathrm{m}$ pulse spacing. This is potentially due to the shielding of the incoming laser beam by interaction of the next impinging laser pulses with the still existent plasma/particle plume induced by subsequent pulse irradiation(s). With the higher scan speed of $192 \mathrm{~m} / \mathrm{s}$ both processing quality and removal efficiency could be improved, as shown in Fig. $11 \mathrm{c}$. The latter might result from heat accumulation thus enhancing material removal reported previously $[12,13]$. By further increasing pulse spacing and scan speed, the processing quality was still excellent but both the specific removal rate and removal efficiency reduced.
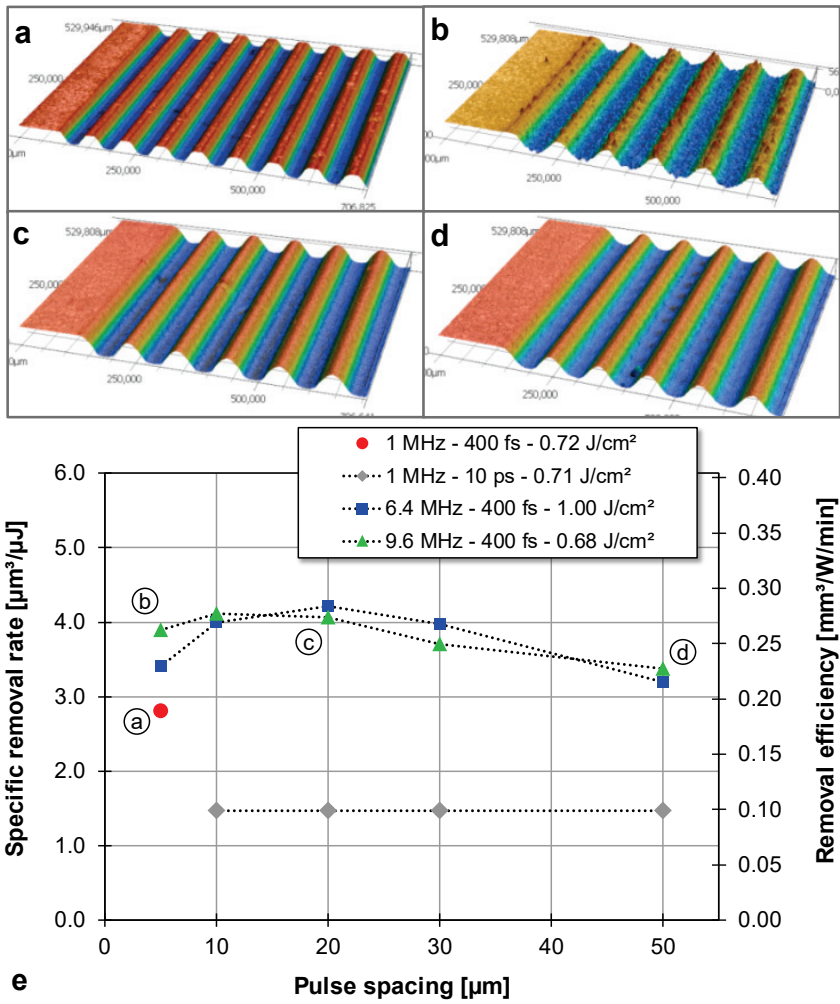

Fig. 11 Riblets machined in AISI 304 with $1030 \mathrm{~nm}$ femtosecond laser pulses and a) $3 \mathrm{~W}, 1 \mathrm{MHz}, 5 \mathrm{~m} / \mathrm{s}$; b) $60 \mathrm{~W}, 9.6 \mathrm{MHz}, 48 \mathrm{~m} / \mathrm{s}$; c) $60 \mathrm{~W}, 9.6 \mathrm{MHz}, 192 \mathrm{~m} / \mathrm{s}$; d) $60 \mathrm{~W}, 9.6 \mathrm{MHz}, 480 \mathrm{~m} / \mathrm{s}$; e) specific removal rate and removal efficiency vs. lateral pulse spacing, the Riblets a-d are referenced in e, dotted lines guide the eye.

This is pointed out in Fig. $11 \mathrm{~d}$ and e by the targeted $62 \mu \mathrm{m}$ Riblets produced at $480 \mathrm{~m} / \mathrm{s}$ scan speed and $9.6 \mathrm{MHz}$ pulse repetition frequency. An explanation therefore can be seen in the applied high beam moving speed as the irradiated pulses moved ahead from the induced isotherms that, in turn, lowered the contribution/effectiveness of heat accumulation on material removal. In addition, almost identical removal rates were achieved for both $6.4 \mathrm{MHz}$ and 9.6 $\mathrm{MHz}$ repetitive pulses. From this, it can be suggested that heat accumulation and particle shielding effects will be balanced at such high $\mathrm{MHz}$ pulse repetition frequencies. As another effect, the plot in Fig. 11 e confirms about 2.5 times higher removal efficiency for femtosecond pulses than for picosecond pulses, which is conformal to results achieved in earlier studies [14]. 
Power scaling of the area processing rate for the considered Riblets fabricated in EN-AW 5005A is presented in Fig. 12. It can be seen, the effective processing rate for the laser made $62 \mu \mathrm{m}$ Riblet structures of $124 \mu \mathrm{m}$ period increases from $1.5 \mathrm{~cm}^{2} / \mathrm{min}$ at $90 \mathrm{~W}$ to $6.0 \mathrm{~cm}^{2} / \mathrm{min}$ as achieved with $450 \mathrm{~W}$ average (fs) laser power. The area processing rate obtained with the $230 \mathrm{~W}$ picosecond laser beam was considerably lower of about $1.8 \mathrm{~cm}^{2} / \mathrm{min}$ although the irradiated average laser power is about the half of the highaverage power femtosecond laser beam.

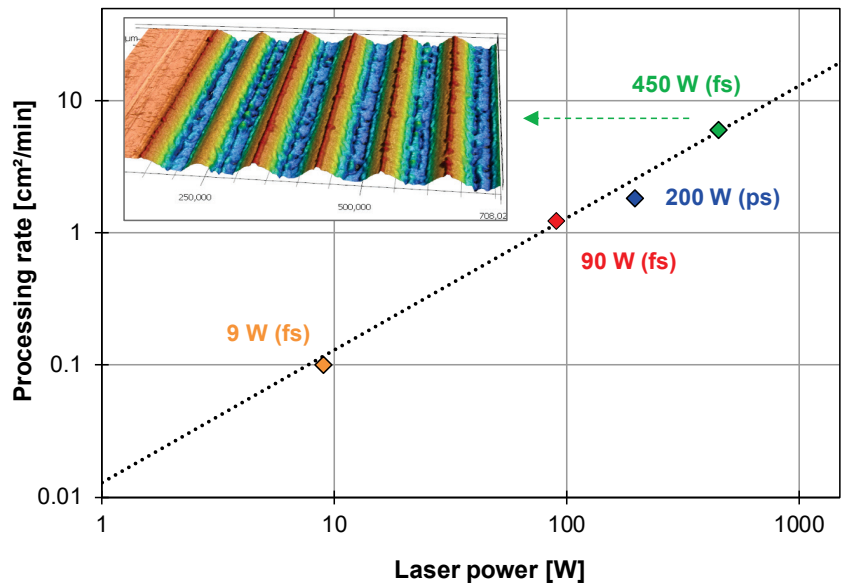

Fig. 12 Power scaling in large-area Riblet production on Aluminum alloy using femtosecond and picosecond laser beams; the dotted line indicates the scaling-up of the effective processing rates with higher laser powers for the targeted $62 \mu \mathrm{m}$ height and $124 \mu \mathrm{m}$ period Riblet geometry.

This fact emphasizes the already above mentioned greater efficiency for femtosecond instead of using picosecond laser pulses in material ablations. The 3D topography micrographs in the plot indicate material melting that lowers the Riblet quality. It is noteworthy for these very initial results, the fluence of the irradiated pulses was greater than optimum level that was applied here to bring the total of $450 \mathrm{~W}$ available laser powers to the substrate. For this case, the pulse repetition frequency was already set to maximum of $40 \mathrm{MHz}$ and beam moving speed was ultrafast $560 \mathrm{~m} / \mathrm{s}$. A further improvement of the processing strategy can be seen in the combination of parallel processing using DOE (diffractive optical element) in combination with ultrafast (polygon scanner based) laser beam movements. This novel machining strategy has already been successfully demonstrated in large-area surface texturing [15] and will be investigated in high-precision surface profiling in future studies.

\subsection{Functional testing of laser made Riblets}

The functional testing of the laser made Riblets doublesided processed on flat metal plates ( $\mathrm{AlMg} 4,5 \mathrm{Mn})$ was conducted in a Goettingen-type wind tunnel under turbulent air flow conditions. Fig. 13 depicts the real profiles of the tested laser made Riblets (red lines). In addition, the ideal trapezoidal Riblet geometry is indicated by black lines with the following characteristic profile values: Plate 1 and Plate 2 with $124 \mu \mathrm{m}$ Riblet spacing and $62 \mu \mathrm{m}$ Riblet height, Plate 3 with $178 \mu \mathrm{m}$ Riblet spacing and $79 \mu \mathrm{m}$ Riblet height. It can be seen, the profile of the laser made Riblets on Plate 1 deviates significantly from the ideal trapezoidal Riblet geometry.
This resulted primarily from the limited spatial resolution of the $46 \mu \mathrm{m}$ larger spot size of the focused $1030 \mathrm{~nm}$ laser beam.

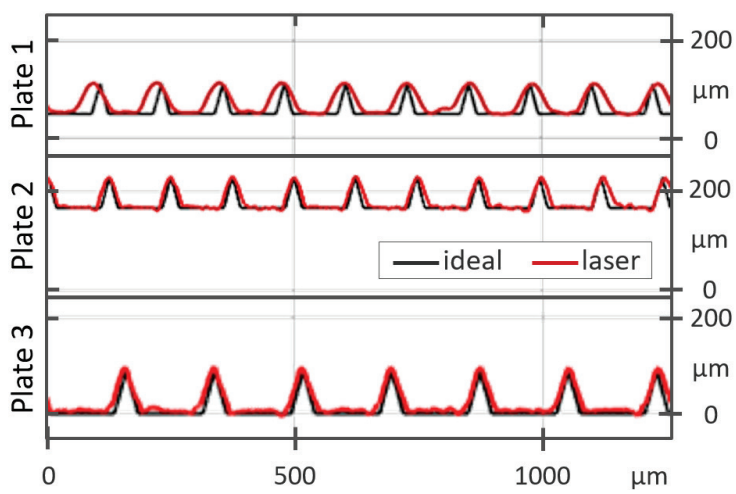

Fig. 13 Profile data of the laser made Riblets produced on the flat metal plates for wind tunnel testing. The ideal trapezoidal Riblet geometry is indicated by the black lines.

However, with $84.2 \mathrm{~W}$ average laser power and $140 \mathrm{~m} / \mathrm{s}$ scan speed applied here for Riblet processing the highest effective processing rate of $1.5 \mathrm{~cm}^{2} / \mathrm{min}$ was achieved. By contrast, Fig. 13 displays the profile of the Riblets produced on Plate 2 and Plate 3 in good conformity to the ideal Riblet profile. In this case, the $515 \mathrm{~nm}$ laser beam was focused to a smaller $25 \mu \mathrm{m}$ spot size for the Riblet processing. The applied average laser power to produce the high-quality Riblets was only $8.2 \mathrm{~W}$ irradiated at $12.7 \mathrm{~m} / \mathrm{s}$ scan speed. Therewith, the effective processing rates were achieved of $0.47 \mathrm{~cm}^{2} / \mathrm{min}$ and $0.33 \mathrm{~cm}^{2} / \mathrm{min}$ for the Riblet profiling on Plate 2 and Plate 3 , respectively.

The drag reducing effect of the laser processed metal plates can be seen in Table 1. Therein, the total pressure loss reduction determined in the wind tunnel measurements as well as drag reduction obtained in both the empirical-analytical and Computational Fluid Dynamic analysis are presented. For comparison, the drag reduction computed for the ideal Riblet geometry is given in this table. The difference in the predicted total pressure loss reduction $\Delta \omega / \omega_{0}$ for the identical ideal Riblet profile on Plate 1 and 2 was due to the different size of the considered laser processed surface area. The deviation of the total pressure loss reduction for the ideal Riblets on Plate 3 in comparison to Plate 2 resulted from the different Riblet size and from additional variation of the flow conditions.

Table 1 Summary of drag reductions achieved in the wind tunnel measurements as well as determined in the empirical-analytical and Computational Fluid Dynamic analyses.

\begin{tabular}{|c|c|c|c|c|}
\hline \multicolumn{2}{|c|}{} & Plate 1 & Plate 2 & Plate 3 \\
\hline \multirow{3}{*}{$\Delta \omega / \omega_{\mathbf{0}}$} & wind tunnel & $-0.79 \%$ & $-1.76 \%$ & $-0.22 \%$ \\
\cline { 2 - 5 } & CFD & $-0.87 \%$ & $-1.73 \%$ & $-2.21 \%$ \\
\hline \multirow{3}{*}{$\Delta \tau / \tau_{0}$} & empirical & $-4.24 \%$ & $-5.45 \%$ & $-6.01 \%$ \\
\cline { 2 - 5 } & $\mathbf{C F D}$ & $-4.45 \%$ & $-5.35 \%$ & $-6.43 \%$ \\
\hline \multirow{2}{*}{$\begin{array}{c}\text { ideal } \\
\text { Riblet }\end{array}$} & $\boldsymbol{\Delta} \tau / \boldsymbol{\tau}_{\mathbf{0}}$ & $-7.90 \%$ & $-7.90 \%$ & $-7.90 \%$ \\
\cline { 2 - 5 } & $\boldsymbol{\Delta} \omega / \omega_{\mathbf{0}}$ & $-1.42 \%$ & $-2.49 \%$ & $-2.82 \%$ \\
\hline
\end{tabular}

For all the tested laser made Riblet profiles a remarkable drag reducing effect could be verified that is within the range of expectations for ideal Riblet geometries. In the wind tunnel measurements, the highest drag reduction of $-1.76 \%$ was 
achieved with the Riblet profile Plate 2. Herewith, the experimentally determined drag reduction is in good agreement with the computed data. Only for Plate 3, the modelled pressure loss coefficient $\Delta \omega / \omega_{0}$ could not be confirmed by the wind tunnel measurements. However, for this Riblet profile produced on Plate 3 it is noteworthy that both the empirical-analytical approach and also the CFD method showed the highest drag reducing effectiveness. This discrepancy will be clarified in the ongoing study.

As already stated above, it should be emphasized here again that the functionality of the Riblets highly depends on the ratio between top width and Riblet spacing. In this context, the drag reducing effect of the laser made Riblets tested in this study is compared to literature references. This is pointed out in Fig. 14 showing the drag reducing effect determined in the empirical-analytical approach and the CFD analysis for the laser made Riblet profiles tested here is in line with the reduction of the wall shear stresses experienced in earlier engineering studies [16].

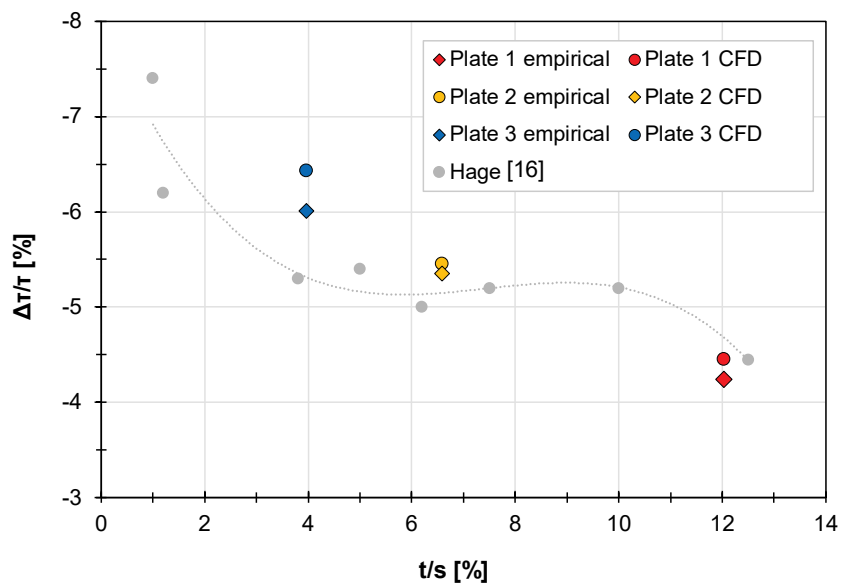

Fig. 14 Wall shear stress reduction $\Delta \tau / \tau$ as function of the ratio between Riblet top width and Riblet spacing; the wall shear stress reduction for Plate 1, Plate 2 and Plate 3 was obtained by considering the respective Riblet profile in the empirical-analytical and the CFD analyses; reference data from the literature are included [16].

Moreover, the laser made high-quality Riblet profiles presented in this work showed a more than twice higher skin friction drag reduction when comparing with previously laser-profiled Riblets tested in an oil channel [3]. As another positive effect of the high-rate laser processing technology applied here, the processing rates could be considerably increased by at least a factor of 20 for the $90 \mathrm{~W}$ or rather almost 100 for the $450 \mathrm{~W}$ femtosecond laser beam when compared to state-of-the-art laser processing.

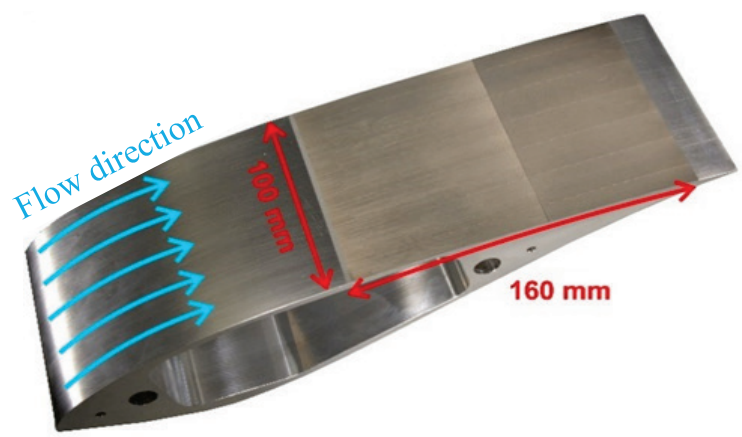

Fig. 15 Riblets produced on a NREL S819 airfoil (AlMg4,5Mn), the laser processed surface area is $160 \mathrm{~mm} \times 100 \mathrm{~mm}$.
These high processing rates attract the high-precision laser surface profiling method to be applied in modern micro fabrication. Therefore, as a first machining example given in Fig. 15, the Riblets were produced on a NREL-S819 airfoil thus to demonstrate the high potential of the laser profiling technology for innovative industrial applications in the energy machinery sector.

\section{Conclusion}

High-precision surface profiling was investigated in order to fabricate high-quality trapezoidal Riblet structures with potential for drag reduction in turbulent flows. At first, in the fundamental study, optimum laser machining conditions were defined to fabricate Riblets of pre-specified geometry for best functionality. The laser made Riblets were tested in a Goettingen-type wind channel but also in empirical-analytical and CFD analyses in order to evaluate their effectiveness for skin friction and total pressure loss reductions. A remarkable total pressure loss reduction as high as $1.76 \%$ was achieved in the wind tunnel measurements for the flat plates covered with optimal laser processed Riblet structures. The CFD analysis showed a maximum skin friction reduction of $6.43 \%$ for the laser made Riblet profiles. Applying the high-rate laser technology by combining highaverage power ultrashort pulse lasers and polygon-mirror based ultrafast scan systems for Riblet profiling, an effective processing time of $6.0 \mathrm{~cm}^{2} / \mathrm{min}$ was reached. This is almost a factor 100 faster when comparing with state-of-the-art laser technologies. Furthermore, it was demonstrated in this study that the processing rates can be scaled-up with higher laser powers. So, in future, much greater processing rates can be expected for the higher available average laser powers applied in (parallel) ultrafast laser beam scanning. As a first machining example, the Riblets were produced on a NREL-S819 airfoil thus to demonstrate the high potential of the laser profiling technology for innovative industrial applications in the energy machinery sector.

\section{Acknowledgments}

This research was supported by the project "OstrALas - Optimierung der stroemungsmechanischen Auslegung von Energiemaschinen durch Einsatz von Hochrate-Laser-Strukturierungstechnologien" (03PSIPT1A) funded by the German Federal Ministry of Education and Research.

\section{References}

[1] U. Loeschner, J. Schille, A. Streek, T. Knebel, L. Hartwig, R. Hillmann and C. Endisch: Journal of Laser Applications, 27, (2015) S29303.

[2] J. Schille, L. Schneider, A. Streek, S. Kloetzer and U. Loeschner: Optical Engineering, 55(9), (2016) 096109.

[3] K. Oehlert, J.R. Seume, F. Siegel, A. Ostendorf, B. Wang, B. Denkena, T. Vynnyk, E. Reithmeier, W. Hage, K. Knobloch and R. Meyer: Proc. of the ASME 2007 International Mechanical Engineering Congress and Exposition, Vol. 1: Advances in Aerospace Technology, Seattle, (2007) p. 25.

[4] K.M. Ahmmed, J. Montagut and A. Kietzig: Can. J. Chem. Eng., 95, (2017) 1934.

[5] A. Zemaitis, J. Miksys, M. Gaidys, P. Gecys and M. Gedvilas: Mater. Res. Express, 6, (2019) 065309. 
[6] D. Bechert, M. Bruse, W. Hage and R. Meyer: Naturwissenschaften, 87, (2000) 157.

[7] G. Raciukaitis, M. Brikas, P. Gecys, B. Voisiat and M. Gedvilas: JLMN-Journal of Laser Micro/Nanoengineering, 4, (2009) 186.

[8] B. Neuenschwander, G. Bucher, Ch. Nussbaum, B. Joss, M. Muralt, U. Hunziker and P. Schuetz: SPIE LASE, Proc. SPIE, 7584, (2010) 75840R.

[9] J. Schille, L. Schneider, L. Hartwig, U. Loeschner, R. Ebert, P. Scully, N. Goddard and H. Exner: ICALEO, (2012) M1003

[10] E. Audouard, J. Lopez, B. Ancelot, K. Gaudfrin, R. Kling and E. Mottay: Journal of Laser Applications, 29, (2017) 022210.

[11] K. Oehlert, C.A. Million and K. Hartung: Journal of Energy and Power Engineering, 12, (2018) 289.
[12] J. Schille, R. Ebert, U. Loeschner, P. Regenfuss, T. Suess and H. Exner: Proc. 9th Int. Symp. on Laser Precision Microfabrication, Quebec, (2008) 0857-64.

[13] J. Schille, L. Schneider, U. Loeschner, R. Ebert, P. Scully, N. Goddard, B. Steiger and H. Exner: ICALEO, (2011) M102.

[14] P. Lickschat, J. Schille, R. Ebert, H. Exner and S. Weissmantel: ICALEO, (2012) 1261.

[15] J. Schille, S. Mauersberger, L. Schneider and U. Loeschner: The Laser User, 92, Spring 2019

[16] W. Hage: Dissertation "Zur Widerstandsverminderung von dreidimensionalen Riblet-Strukturen und anderen Oberflächen", Technische Universität Berlin, Mensch und Buch Verlag, (2005).

(Received: October 2, 2019, Accepted: February 4, 2020) 